\title{
Engineering Practice of Ultra-high Pressure Hydraulic Slotting and Pressure Relief Pumping in Through Layer Hole
}

\author{
Siqian $\mathrm{Li}^{1,2}, \mathrm{a}^{*}$ \\ ${ }^{1}$ State Key Laboratory of Gas Disaster Monitoring and Emergency Technology, Chongqing 400037,China; \\ ${ }^{2}$ China Coal Technology and Engineering Group Chongqing Research Institute, Chongqing 400037, China
}

\begin{abstract}
In order to solve the problems of low gas drainage rate and long drainage time in thick coal seam with low permeability, ultra-high pressure hydraulic slotting pressure relief and permeability enhancement technology was applied in the test. The practice shows that after adopting the ultra-high pressure hydraulic slotting, the gas drainage rate is greatly improved, the time for reaching the standard of drainage is shortened, and the difficult problem of gas control in the mining face of thick coal seam is solved, which provides technical guidance for high-efficiency gas control in thick coal seam with similar conditions in mining area.
\end{abstract}

\section{Introduction}

Most of the coal seams in China belong to low permeability coal seams. There are some problems in pre drainage boreholes, such as low gas concentration, small flow rate, and long time for reaching the standard of drainage. Moreover, limited gas drainage effect is often obtained at the cost of huge engineering amount ${ }^{[1,2]}$. For a single low permeability coal seam, the method of pressure relief and permeability enhancement is needed to improve the permeability of coal seam. At present, the main methods to improve the permeability of coal seam are loose blasting, hydraulic reaming, hydraulic fracturing and other pressure relief and permeability increasing measures, which are well applied in different mining areas, but have certain limitations ${ }^{[3]}$. In recent years, with the continuous development of water jet technology, the ultra-high pressure hydraulic slotting pressure relief and permeability enhancement technology has become a more effective method for pressure relief and permeability enhancement of the coal seam. The technology uses the jet beam with high energy accumulation to impact the coal and rock mass for cutting, resulting in a large number of cracks, so as to achieve the purpose of pressure relief and permeability enhancement of coal seam ${ }^{[4,5]}$.

Aiming at the problems of low gas drainage rate and long drainage time in thick coal seam, taking 1415A working face of No.1 Coal Seam in Zhangji coal mine as the engineering background, the pressure relief and permeability enhancement technology of ultra-high pressure hydraulic slotting through layer drilling was tested in 1415A bottom drainage roadway, and good results were achieved.

\footnotetext{
a Corresponding author: siqian_licqmk@163.com
}

\section{Ultra high pressure hydraulic slotting technology}

\subsection{Technical principle}

Under the cutting action of high-pressure water jet, part of the coal around the borehole is shot down and washed away by high-pressure water jet, forming a flat slot space. These slots are equivalent to mining a very thin protective layer in local scope, increasing the exposed area of coal body, changing the original stress of coal body, fully relieving the pressure of coal body, effectively improving the gas flow state in the coal seam. It creates favorable conditions for gas emission, improves the permeability and gas release capacity of coal seams, weakens or eliminates outburst power, and effectively prevents the occurrence of coal and gas dynamic disasters ${ }^{[6-8]}$. The schematic diagram of hydraulic slotting principle is shown in Figure 1.

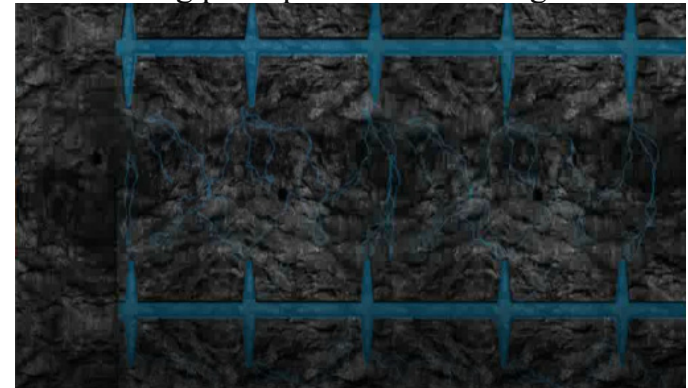

Figure 1. Schematic diagram of hydraulic slotting technology.

\subsection{Supporting equipment}

The ultra-high pressure hydraulic slotting device includes 
ultra-high pressure water pump, ultra-high pressure rotary joint, hydraulic slotting shallow spiral drill pipe, high and low pressure converter, diamond hydraulic slotting bit, ultra-high pressure hose, water tank, etc.

\section{Field test}

\section{1 test site}

The test site is $1415 \mathrm{~A}$ working face of 1 coal seam. The thickness of the coal seam is $6.8-9.6 \mathrm{~m}$ with an average thickness of $7.8 \mathrm{~m}$. The dip angle of the coal seam is $3^{\circ}$ to $8^{\circ}$ with an average of $5^{\circ}$. The coal seam structure is simple without gangue.The roof and floor are mainly composed of mudstone and siltstone (fine) sandstone, with gas content of $3.8-5.2 \mathrm{~m}^{3} / \mathrm{t}$, gas pressure of $0.3-0.5 \mathrm{MPa}$. When the working face is mined near the fault, the relative gas emission is large, and the abnormal gas emission near the fault usually shows the characteristics of "single hump" curve.

\subsection{Test scheme and slotting process}

\subsubsection{Borehole layout}

Two groups of slotted boreholes and two groups of uncut boreholes were constructed in floor roadway, and the pressure relief and permeability enhancement effect of ultra-high pressure hydraulic slotting was studied and analyzed. Five boreholes are arranged in each group, the spacing is $20 \mathrm{~m}$, the dip angle is $21^{\circ}$ to $45^{\circ}$ and the hole depth is $33 \sim 77 \mathrm{~m}$. The plane layout of boreholes is shown in Figure 2.

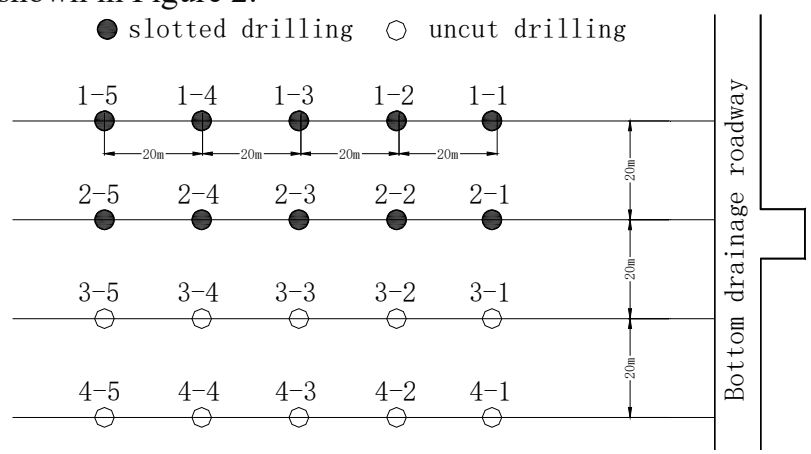

Figure 2. Examines the layout of boreholes

\subsection{2 slotting process}

(1) The drill bit with diameter of $113 \mathrm{~mm}$ was drilled to the design depth with hydrostatic water.

(2) After the drilling construction is in place, the high-pressure water pipe is replaced, the high-pressure water pump is turned on, and the working pressure is modulated to $90-95 \mathrm{mpa}$. The coal body around the coal seam is cut by high-pressure water jet, and the seam spacing is $1.5 \mathrm{~m}$.

(3) During the slotting period, pay attention to the backwater and slag at the orifice. When the backwater changes from black to clear, close the high-pressure clean water pump and control the stop valve. After the pipeline is depressurized, remove 2 drill pipes and re connect the high-pressure pipeline.

(4) Repeat the above steps (2) and (3) to complete the drilling and slotting.

(5) After the slotting is completed, the high-pressure water pump shall be shut down in time. After the pressure is fully relieved, the drill pipe shall be removed and stacked in order, and the slotting equipment shall be properly kept.

The conventional construction technology is used for the construction of non slotted drilling.

\section{Test effect investigation}

This paper selects equivalent diameter, gas flow, gas drainage volume and residual gas content to analyze the test effect of ultra-high pressure hydraulic slotting.

\subsection{Comparative analysis of equivalent diameter of boreholes}

According to the statistics of chip removal amount of slotted drilling and non slotted drilling, the equivalent diameter after drilling construction is calculated respectively, as shown in Figure 3.

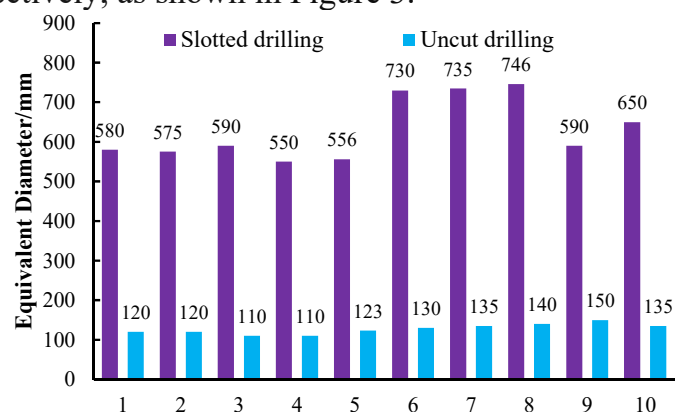

Figure 3. Equivalent diameters of slotted and uncut boreholes

According to the analysis in Figure 3, the equivalent diameter of slotted hole is $550-746 \mathrm{~mm}$, with an average of $630 \mathrm{~mm}$, while that of non slotted hole is $117-136 \mathrm{~mm}$, with an average of $124 \mathrm{~mm}$. The equivalent diameter of slotted hole is about 5 times of that of uncut hole. After using the high pressure hydraulic cutting technology, a large number of coal chips are discharged from the orifice, and different width slots are formed in the borehole, which changes the stress state of coal body and creates favorable conditions for gas flow.

\section{2 comparative analysis of borehole gas flow}

In this test, six boreholes are selected to measure the gas flow rate from slotted boreholes and non slotted boreholes, as shown in Figure 4. 


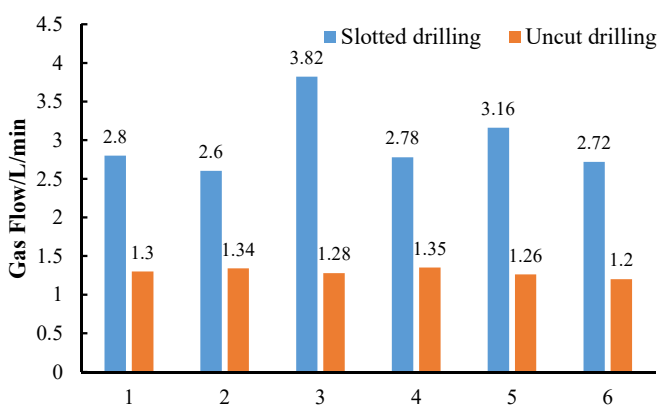

Figure. 4 Gas flow in slotted and uncut boreholes

According to the analysis in Figure 4, the average gas flow of slotted boreholes is $2.98 \mathrm{~L} / \mathrm{min}$, and that of uncut boreholes is $1.29 \mathrm{~L} / \mathrm{min}$. After slotting, the exposed area of coal body in drilling hole is increased, the fracture in coal body is developed, the gas flow state in coal seam is improved, and the gas flow rate is increased by 2.3 times.

\subsection{Comparative analysis of gas drainage amount}

Within 20 days of borehole pumping, the variation trend of drainage concentration and flow rate of slotted and uncut boreholes are shown in Figure 6.

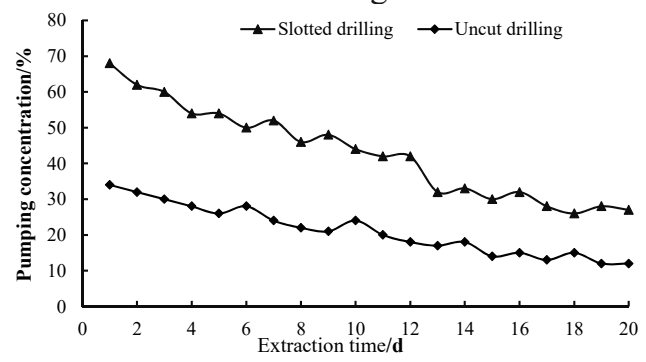

Drainage gas concentration

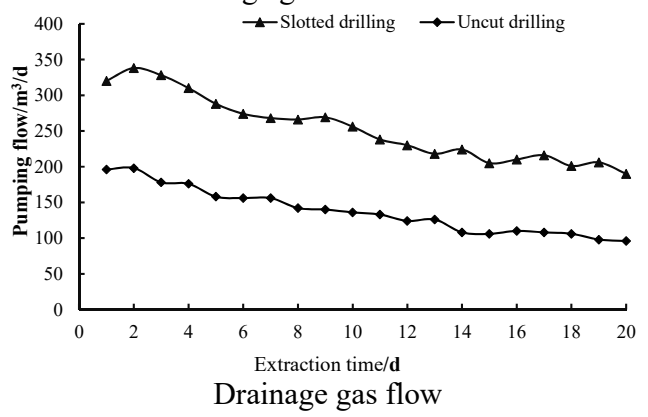

Figure.5 Variation trend of gas concentration and flow in slotted and uncut boreholes

According to the analysis in Figure 5, the gas drainage volume and concentration of the slotted borehole are 1.6-2.0 times and 2.0-2.25 times of that of the uncut drilling hole, and the average drainage amount of a single hole is 1.8 times of that of the uncut drilling hole. It is confirmed that the pressure relief range around the borehole increases, the drainage range expands, and the gas drainage volume increases greatly in the same time.

\subsection{Comparative analysis of residual gas content}

The original gas content in the test area is $5.2 \mathrm{~m}^{3} / \mathrm{t}$. After 15 days and 30 days of pre drainage, the residual gas content in the slotted area is $4.31 \mathrm{~m}^{3} / \mathrm{t}$ and $3.56 \mathrm{~m}^{3} / \mathrm{t}$ respectively, and the gas content reduction rate is $19 \%$ and $32 \%$, respectively. The residual gas content in the non slotted area is $4.67 \mathrm{~m}^{3} / \mathrm{t}$ and $4.22 \mathrm{~m}^{3} / \mathrm{t}$ respectively, and the gas content decline rate is $19 \%$ and $32 \%$ respectively. After using high pressure hydraulic cutting, the original stress of coal body is changed, the coal body is fully depressurized, the permeability of coal body is increased, the gas drainage flow and concentration are increased, and the pre drainage time of drilling hole is shortened.

\section{Conclusion}

(1) The practice shows that the high-pressure hydraulic slotting technology can effectively increase the exposed area of the drilled coal body, fully relieve the pressure of the coal body, promote the development of the fracture, and provide favorable conditions for the gas release. The gas drainage concentration and volume of the borehole are greatly increased, which reduces the engineering amount of the drilling hole and shortens the drainage time.

(2) The test of high pressure hydraulic slotting technology successfully solved the difficult problem of gas control in No.1 Coal Seam of Zhangji coal mine, which can be further popularized and applied; at the same time, it provides technical support for efficient gas control and safe and efficient mining.

\section{Acknowledgments}

General project of Chongqing Research Institute Co., Ltd(2020YBXM22)

\section{Reference}

1.Yuan Liang.Key technique of safe mining in low permeability and methane-rich seam group $[\mathrm{J}]$.Chinese Journal of Rock Mechanics and Engineering,2008(07):1370-1379.

2.Yuan Liang,Lin Baiquan, Yang Wei.Research progress and devclopment direction of gas control with mine hydraulic techonology in China coal mine[J]. .Coal Science and Technology,2015,43(01):45-49.

3.Shu Sheng,Li Qiulin.Application of deep hole loose blasting technology in driving face of difficult mining seam[J].Mining Safety \& Environment Protection, 2010,37(05):65-67+70.

4.Xu Jingde,Yang Fang,Lai fangfang.ect.Present situation and development of permeability improvement technology for enhanced gas drainage in our coal mines[J].Mining Safety \& Environment Protection,201441(04):100-103.

5.Zhang Yongjiang,Meng Xianzheng Ji Fei.Study and application of antrireflection technology for ultra-high pressure hydraulic slitting of long bedding borehole[J].Mining Safety \& Environment Protection, 2018,45(05):1-5+11.

6.Liu Zhiwei,Zhao Jinming,Zhang Yangqiang,ect.Investigation and application on the effect of pressure relived and permeability enhanced of ultra-hing pressure hydraulic slotting in lvtang coal mine[J].Mining Safety \& Environment Protection,2019,46(01):43-46. 
7.Tong Bi,Wang Li.Study and application of hydraulic slotting construction technology for downward through hole[J].Coal Science and Technology,2017,45(8):177-180,188.

8.Wu Jiaokun.Application of hydraulic kerf technology in shimen uncovering coal[J].Coal Mining,2017,22(2): 93-95. 